\title{
Feather bedding and childhood asthma associated with house dust mite sensitisation: a randomised controlled trial
}

\author{
Nicholas J Glasgow, ${ }^{1}$ Anne-Louise Ponsonby, ${ }^{1,2}$ Andrew Kemp, ${ }^{3}$ Euan Tovey, ${ }^{4}$ \\ Peter van Asperen, ${ }^{3,5}$ Karen McKay, ${ }^{3,5}$ Samantha Forbes ${ }^{5}$
}

\begin{abstract}
${ }^{1}$ Medical School, The Australian National University, Acton, Australia ${ }^{2}$ Murdoch Childrens Research Institute, Royal Children's Hospital, Parkville, Victoria, Australia

${ }^{3}$ Discipline of Paediatrics and Child Health, Sydney Medical School, University of Sydney, The Children's Hospital at Westmead Clinical School, Sydney, New South Wales, Australia

${ }^{4}$ Woolcock Institute of Medical Research, Sydney, New South Wales, Australia

${ }^{5}$ Department of Respiratory Medicine, The Children's Hospital at Westmead, Westmead, New South Wales, Australia
\end{abstract}

\section{Correspondence to}

Professor Nicholas J Glasgow, Building 42, The Australian National University, Acton 0200 ACT, Australia; nicholas.glasgow@anu.edu.au

Accepted 4 February 2011 Published Online First 30 March 2011

\section{ABSTRACT \\ Introduction Observational studies report inverse} associations between the use of feather upper bedding (pillow and/or quilt) and asthma symptoms but there is no randomised controlled trial (RCT) evidence assessing the role of feather upper bedding as a secondary prevention measure.

Objective To determine whether, among children not using feather upper bedding, a new feather pillow and feather quilt reduces asthma severity among house dust mite (HDM) sensitised children with asthma over a 1-year period compared with standard dust mite avoidance advice, and giving children a new miteocclusive mattress cover.

Design RCT.

Setting The Calvary Hospital in the Australian Capital Territory and the Children's Hospital at Westmead, Sydney, New South Wales.

Patients 197 children with HDM sensitisation and moderate to severe asthma.

Intervention New upper bedding duck feather pillow and quilt and a mite-occlusive mattress cover (feather) versus standard care and a mite-occlusive mattress cover (standard).

Main outcome measures The proportion of children reporting four or more episodes of wheeze in the past year; an episode of speech-limiting wheeze; or one or more episodes of sleep disturbance caused by wheezing; and spirometry with challenge testing. Statistical analysis included multiple logistic and linear regression.

Results No differences between groups were found for primary end points - frequent wheeze (OR 1.51, 95\% Cl 0.83 to $2.76, p=0.17$ ), speech-limiting wheeze (OR 0.70 , $95 \% \mathrm{Cl} 0.32$ to $1.48, p=0.35)$, sleep disturbed because of wheezing (OR 1.17, 95\% $\mathrm{Cl} 0.64$ to $2.13, \mathrm{p}=0.61$ ) or for any secondary end points. Secondary analyses indicated the intervention reduced the risk of sleep being disturbed because of wheezing and severe wheeze to a greater extent for children who slept supine.

Conclusion No differences in respiratory symptoms or lung function were observed 1 year after children with moderate-severe asthma and HDM sensitisation were given a mite-occlusive mattress cover and then received either feather upper bedding (pillow and quilt) or standard bedding care.

\section{INTRODUCTION}

Over the past two decades, studies have reported an inverse association between feather upper bedding and asthma symptoms. ${ }^{1-4}$ In Australia, we found that this inverse association is stronger in house

\section{What is already known on this topic}

- Observational epidemiological studies have reported that children who sleep with feather pillows and quilts have lower rates of wheeze.

- Feather bedding has been reported to have lower Der $\mathrm{p} 1$ dust mite levels than synthetic bedding.

- Child sleep position has been shown to alter the association between upper bedding type and wheeze.

\section{What this study adds}

- New feather bedding was not associated with an altered risk of wheeze symptoms lung function or quality of life after 12 months.

- This trial does not support recommendations that feather bedding should be avoided for children with asthma.

- Child sleep position should be taken into account for trials examining the bedding environment and asthma.

dust mite (HDM) sensitised children. ${ }^{5}$ In a North European birth cohort, children using feather bedding by age 4 were less likely to develop wheeze. ${ }^{6}$

Synthetic bedding may be more adverse than feather bedding because synthetic bedding may have higher levels of HDM allergens, ${ }^{7} 8$ proinflammatory fungal cell wall $\beta$-(1,3)-glucans, ${ }^{9}$ volatile organic compounds, ${ }^{1}$ and lower levels of bacterial endotoxins. ${ }^{10}$ Alternatively, the association between synthetic bedding and wheeze in one study was partly accounted for by changes in bedding which occurred after the development of wheeze. ${ }^{11}$ A 2007 Cochrane review could not identify any randomised controlled trial (RCT) evidence assessing the role of feather upper bedding as a secondary prevention intervention in asthma. ${ }^{12}$ Previously, randomised trials have shown that HDM reduction strategies have not been effective, even among the subset of trials that have documented HDM reduction on mattresses. ${ }^{13}$ This may indicate that other aspects of a child's environment such as upper bedding may be important. The conflicting findings about bedding interventions and asthma may also reflect that there are modifiers of the association between 
bedding and wheeze. For example, we have previously shown that the adverse effect of synthetic quilt use on child wheeze or lung function is substantially more evident for children who sleep supine compared with those who do not. ${ }^{14}$

Here, we report on an RCT to determine whether, among children not using feather upper bedding, a new feather pillow and quilt (feather) reduces asthma severity among HDM sensitised children with asthma over a 1-year period compared with dust mite avoidance advice ${ }^{15}$ (standard) when all children are also given a new mite-occlusive mattress cover.

\section{METHODS}

\section{Study design}

A RCT was conducted at two sites (Calvary Hospital in the Australian Capital Territory (ACT) and the Children's Hospital at Westmead, Sydney, New South Wales (NSW)).

\section{Methods of recruitment}

Recruitment occurred from January 2002 to December 2004 through advertising in schools, emergency departments, general practices and paediatric respiratory clinics. Written informed consent was obtained from parents or carers.

\section{Trial eligibility}

Eligibility criteria were: aged 7-14 years; diagnosed with asthma; asthma symptoms including wheeze; four or more episodes of wheeze per year or an episode of speech-limiting wheeze in the past 12 months; HDM sensitised ${ }^{16}$ (skin prick test weal size $\geq 3 \mathrm{~mm}$ to Dermatophagoides pteronyssinus and/ or Dermatophagoides farina); not sensitised to feather (weal size $<3 \mathrm{~mm}$ to feather extract); not sensitised to cat pelt (weal size $<3 \mathrm{~mm}$ to cat pelt extract) if there was a cat at home; not having a feather pillow or quilt on their bed at study entry; single bed use; and plan to remain in the study region for the next 2 years.

\section{Trial interview schedule and study sample}

A total of 759 children were assessed for eligibility (figure 1). One hundred and ninety-seven children were randomised, had baseline interviews, spirometric assessments completed and a home visit to apply the bedding changes. Phone interviews were conducted every 3 months with follow-up home visits and clinic assessments at 12 months postintervention. The interviews collected data on respiratory symptoms, quality of life and other factors such as usual sleep position by asking: 'What position does your child usually sleep in?' and providing options including 'on the back' (supine). ${ }^{14}$

\section{Randomisation and blinding}

Block randomisation with age blocks by year of birth was used. The 'biased coin' method was used to minimise the likelihood that group allocation differed by season. ${ }^{17}$ Patient blinding was achieved by providing interventions to both the feather and standard groups. Each participant, regardless of group allocation, was informed that they had been allocated to a bedding group with some evidence to support its use in asthma. Research nurses conducting clinical assessments were blind to group assignment. An independent statistician, also blind to group assignment, undertook the first analyses.

\section{Feather group}

Parents and children were supplied with and instructed to use only the feather upper bedding (pillow and quilt), with no other forms of upper bedding apart from sheets. On hot nights, the replacement use of thin cotton covers was permitted. Standard commercial practice meant the duck feather and down bedding had been prewashed in hot water, chemically treated and hot air dried by the manufacturer before use, with documentation of the procedures used (Myer House Brand, Hangzhou, China).

Feather pillows were used all year. A mite-occlusive cover (Auspharm, Surrey Hills, NSW, Australia) was fitted to the mattress.

\section{Standard group}

This group received verbal and written advice from the research nurse at baseline explaining the bedding advice from the National Asthma Campaign (applicable at the time). ${ }^{15}$ This included the use of pillow, quilt and mattress mite-proof covers, weekly washing of bedclothes in hot (over $55^{\circ} \mathrm{C}$ ) water and weekly dusting of bedrooms using damp cloths. A mite-occlusive cover (Auspharm) was also fitted to the mattress.

\section{Trial outcome measures}

Based on previous Australian reports, ${ }^{5} 14$ primary end points were measured at baseline and at 12 months postintervention. They were: the proportion of children reporting four or more episodes of wheeze; an episode of speech-limiting wheeze; or reporting one or more episodes of sleep disturbed because of wheezing in a week. Each child was assessed using previously validated questions from the International Study of Asthma and Allergy in Childhood. ${ }^{18}$ Secondary end points included spirometry with challenge testing, quality of life assessments using the Juniper Paediatric Quality of Life Questionnaire ${ }^{19}$ and medication use. Spirometry at baseline and end point included forced expiratory volume in $1 \mathrm{~s}\left(\mathrm{FEV}_{1}\right)$, forced vital capacity (FVC), the $\mathrm{FEV}_{1} / \mathrm{FVC}$ ratio and the relative and absolute change in $\mathrm{FEV}_{1}$ after challenge. ${ }^{19}$ For ACT children, the challenge was by cold air for $4 \mathrm{~min}$ at -10 to $-15^{\circ} \mathrm{C}$ (Jaeger cold air system; Wuerzburg, Germany) but for NSW children the challenge was by methacholine. ${ }^{20}$

\section{Environmental outcomes: HDM allergen levels}

In past studies, HDM allergen exposures have often been assessed as the concentration of allergen in dust from bedroom floors and the child's bedding. More recently, airborne or inhaled allergen levels have been used to more accurately measure exposure. Here, inhaled HDM (Der p 1) aeroallergen exposure was sampled using model 2 nasal air samplers (NAS), ${ }^{21}$ worn by children for $10 \mathrm{~min}$ after getting into bed each night, for four nights. A sampling protocol, played on a CD player, describing bed entry and gentle movements, was used to emulate natural sleep disturbance and standardise disturbance. NAS were previously coated internally with an adhesive which collected impacted particles, which were extracted with $0.7 \mathrm{ml}$ of $1 \%$ bovine serum albumin, $0.05 \%$ Tween, phosphate buffered saline buffer and analysed for Der p 1. Additionally, ambient nocturnal aeroallergen exposure was sampled using $25 \mathrm{~mm}$ GF/A glass fibre air filters (Whatman International, Maidstone, UK) as described, ${ }^{22}$ held in an Institute of Occupational Medicine Inhalable Sampling Head (SKC, Dorset, UK), located within 1 metre of the pillow and connected to a diaphragm pump with airflow of 2.0 litre $/ \mathrm{min}$. Samples were managed by an electronic timer and collected for $6 \mathrm{~h}$ after going to bed each night for 4 nights (providing a 


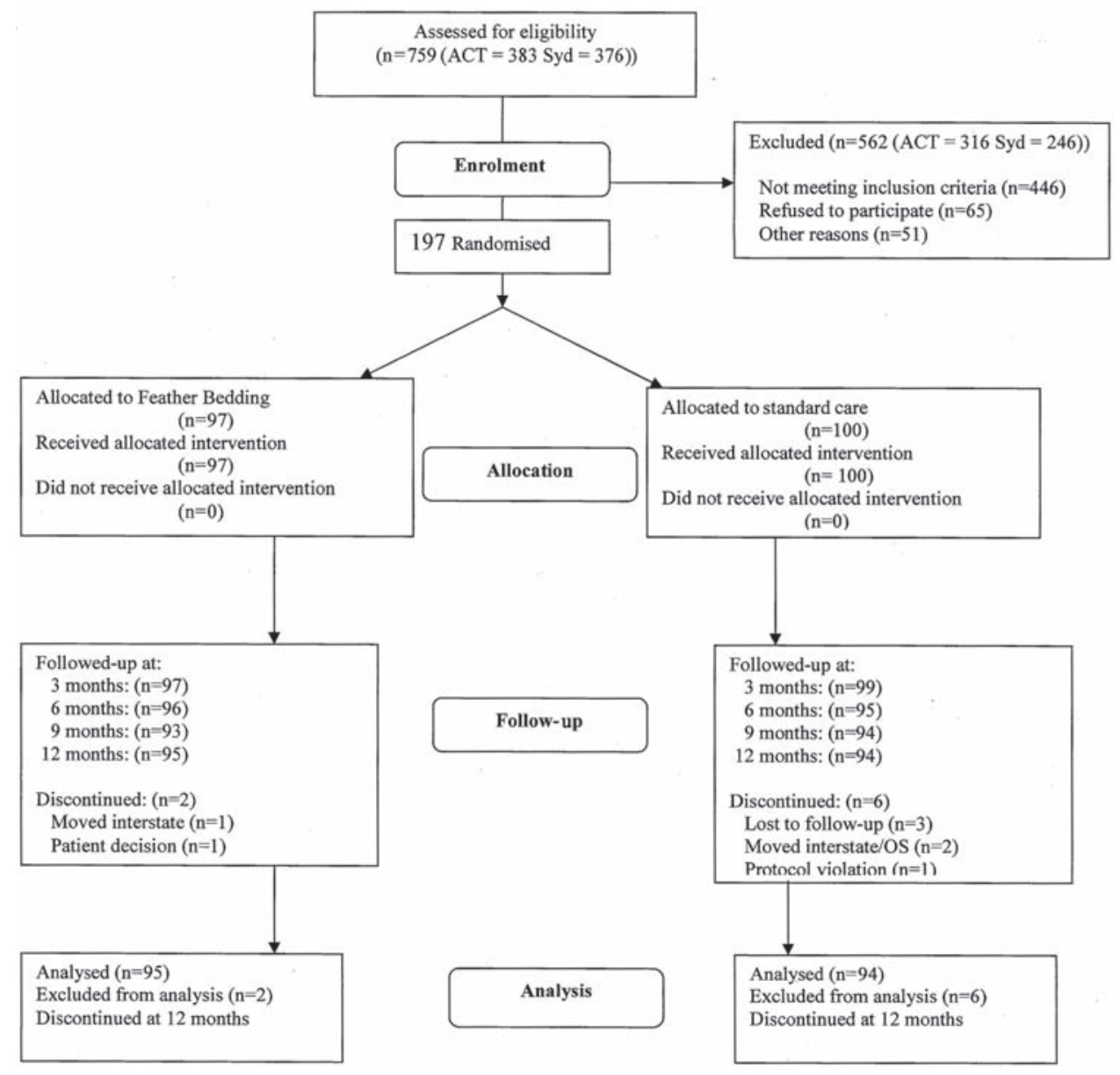

Figure 1 Subject flow diagram.

cumulative 24 h sample in total). Filters were extracted in 1.0 $\mathrm{ml}$ of the same buffer as the NAS.

Der p 1 allergen was measured by a conventional ELISA assay (10B9/5H8) (EL-DP1; Indoor Biotechnologies, Cardiff, UK) modified by the authors to use Poly-HRP80Streptavidin conjugate (RDI, Flanders, New Jersey, USA) and SureBlueTMB Microwell Peroxidase (KPL, Gaithersburg, Maryland, USA) to increase the sensitivity to $9.8 \mathrm{pg} / \mathrm{ml}$. Samples below this were assigned an arbitrary value of 1 $\mathrm{pg} / \mathrm{ml}$ for calculations.

The study was approved by the Human Research Ethics Committee of the Australian Capital Territory Department of Health, the Research Ethics Committee of the Sydney South West Area Health Service, and the Sydney and Human Research Ethics Committee at the Children's Hospital at Westmead, Sydney.

\section{Statistical analyses}

The study aimed to recruit 200 children because this sample would allow the detection of an RR of 0.78 or less associated with feather bedding (an effect size of at least a $22 \%$ reduction) if $90 \%$ of controls reported symptoms of frequent or severe or nocturnal wheeze. ${ }^{51424}$ Also, 178 children would be required to detect a difference in $\mathrm{FEV}_{\mathrm{I}} / \mathrm{FVC}$ ratio of $2.1 \%$ with $\mathrm{p}<0.05$ at $90 \%$ power. $^{25}$ In a previous cross-sectional study, the authors reported that children with HDM sensitisation who slept without a feather quilt had a lower $\mathrm{FEV}_{\mathrm{I}} / \mathrm{FVC}$ ratio than non-HDM sensitised children who slept under a feather quilt (adjusted difference $-0.68 \%, 95 \%$ CI $-1.24 \%$ to $-0.13 \%$ ) but children with HDM sensitisation who slept with a feather quilt did not have a lower $\mathrm{FEV}_{\mathrm{I}} / \mathrm{FVC}$ ratio (adjusted difference $-0.31 \%, 95 \%$ CI $-1.33 \%$ to $0.71 \%) .^{5}$

The main form of analysis was on an intention-to-treat basis. A secondary analysis by compliance was also conducted. Baseline refers to the randomisation visit and end point refers to the final visit at 12 months. The treatment effects for the dichotomous outcomes were assessed using OR estimates from a multiple logistic regression model with adjustment for factors as listed in the table footnotes or additional medication or cover use. The treatment effects for the change in quality of life or lung function tests were assessed using multiple linear regression models.

The assessment of treatment effects by challenge were analysed separately for each site because of the different challenges employed. For the cold air challenge the model used is similar to the one used for change in $\mathrm{FEV}_{1}$ from baseline to end point, except the outcome is the relative/absolute difference in $\mathrm{FEV}_{1}$ because of the challenge.

For the methacholine challenge the outcome of interest is the dose at which the target $\mathrm{FEV}_{1}$ is reached. To evaluate the treatment effect a multiple linear regression model of square root of dose adjusted for baseline value, gender, height and weight was used.

Dose was transformed because of skewness on the raw scale. For analyses based on small numbers, exact $p$ values and CIs were used. 
To assess interaction, the Wald test $p$ value associated with the product term was taken as an indication of the significance of the difference in effect by sleep position. ${ }^{25}$

To accommodate the highly skewed distribution of the dependent variables, environmental Der $\mathrm{p} 1$ allergen measurements between the two bedding groups where compared using the Wilcoxon-Mann-Whitney test. Analyses were conducted using Stata 10 (Statacorp 2007: statistical software: Release 10; College Station, Texas, USA).

\section{RESULTS}

In total, 197 children were randomised with 97 allocated to feather bedding and 100 to standard care. No major differences were observed between the groups (table 1). Overall

Table 1 Baseline characteristics

\begin{tabular}{|c|c|c|}
\hline & Feather bedding ( $\mathrm{N}=97)$ & Standard care $(\mathrm{N}=100)$ \\
\hline Characteristic & $\%(\mathbf{n} / \mathrm{N})$ & $\%(\mathbf{n} / \mathbf{N})$ \\
\hline Female & $42.3(41 / 97)$ & $32.0(32 / 100)$ \\
\hline Study site (ACT vs NSW) & $34.0(33 / 97)$ & $34.0(34 / 100)$ \\
\hline \multicolumn{3}{|l|}{ Age (years) } \\
\hline 7 & $8.6(18 / 97)$ & $12.0(12 / 100)$ \\
\hline 8 & $8.2(8 / 97)$ & $18.0(18 / 100)$ \\
\hline 9 & $19.6(19 / 97)$ & $17.0(17 / 100)$ \\
\hline 10 & $12.4(12 / 97)$ & $18.0(18 / 100)$ \\
\hline 11 & $24.7(24 / 97)$ & $19.0(19 / 100)$ \\
\hline 12 & $13.4(13 / 97)$ & $12.0(12 / 100)$ \\
\hline 13 & $2.1(2 / 97)$ & $4.0(4 / 100)$ \\
\hline 14 & $1.0(1 / 97)$ & $0.0(0 / 100)$ \\
\hline Hospital attendance because of asthma & $87(89.7)$ & $88(88.0)$ \\
\hline Problem with sneezing, runny or blocked nose & $77(79.4)$ & $86(86.0)$ \\
\hline \multicolumn{3}{|l|}{ Wheezing in past 12 months } \\
\hline $1-3$ & $6(6.2)$ & $4(4.0)$ \\
\hline $4-12$ & $47(48.5)$ & $55(55.0)$ \\
\hline More than 12 & $44(45.4)$ & $41(41.0)$ \\
\hline \multicolumn{3}{|l|}{ Sleep disturbed by wheezing in past 12 months } \\
\hline None & $15(15.6)$ & $17(17.0)$ \\
\hline Less than 1 night per week & $54(56.3)$ & $57(57.0)$ \\
\hline One or more nights per week & $27(28.1)$ & $26(26.0)$ \\
\hline Speech-limiting wheeze & $48(49.5)$ & $42(42.0)$ \\
\hline \multicolumn{3}{|l|}{ Medication } \\
\hline Preventers & $92.8(90 / 97)$ & $89.0(89 / 100)$ \\
\hline ICS & $53.6(52 / 97)$ & $54.0(54 / 100)$ \\
\hline ICS + & $43.3(42 / 97)$ & $41.0(41 / 100)$ \\
\hline Relievers & $100.0(97 / 97)$ & $100.0(100 / 100)$ \\
\hline Controllers & $16.0(15 / 97)$ & $11.6(11 / 100)$ \\
\hline Controllers (tablets) & $14.0(13 / 97)$ & $8.7(8 / 100)$ \\
\hline Oral steroids & $67.0(65 / 97)$ & $69.0(69 / 100)$ \\
\hline \multicolumn{3}{|l|}{ Skin prick test (number sensitised) } \\
\hline Standardised cat pelt & $24(24.8)$ & $28(28.6)$ \\
\hline Dermatophagoides pteronyssinus & $93(95.9)$ & $96(98.0)$ \\
\hline Dermatophagoides farinae & $85(87.6)$ & $85(86.7)$ \\
\hline Either house dust mite species & $97(100)$ & $100(100)$ \\
\hline Control & $3(3.1)$ & $2(2.0)$ \\
\hline Histamine & $90(93.8)$ & $94(95.9)$ \\
\hline Rye grass & $45(46.4)$ & $46(46.9)$ \\
\hline Plantain, English & $27(27.8)$ & $24(24.5)$ \\
\hline Smoker in household & $25(25.8)$ & $30(30.0)$ \\
\hline \multicolumn{3}{|l|}{ Number sleeping in child's room } \\
\hline Child only & $66(68.0)$ & $69(69.0)$ \\
\hline Two children & $25(25.8)$ & $28(28.0)$ \\
\hline \multirow[t]{2}{*}{ Three children } & $6(6.2)$ & $3(3.0)$ \\
\hline & Mean (SD) & Mean (SD) \\
\hline Age & $10.2(.79)$ & $10.2(1.69)$ \\
\hline Age of asthma onset & $2.4(1.79)$ & $2.4(2.04)$ \\
\hline Baseline $\mathrm{FEV}_{1} / \mathrm{FVC}$ (\% predicted) & $84(0.10)$ & $83(0.09)$ \\
\hline
\end{tabular}

Notes: no differences in significance for any characteristic between arms at $p<0.05$.

ACT, Australian Capital Territory; FEV , forced expiratory volume in $1 \mathrm{~s}$; FVC, forced volume vital capacity; ICS, inhaled corticosteroids; NSW, New South Wales. 
the mean age for these children was 10.2 years (SD 1.72) and $35 \%(69 / 197)$ of the sample were female. The proportion of children followed up at 12 months was high, with retention rates at 12 months of $98 \%$ (95/97) and 94\% (94/100) for the feather and control groups respectively. No adverse effects were reported among the feather group.

Table 2 shows that compliance after initial allocation was not complete. By trial end, two-thirds of the feather group slept with a feather pillow and quilt and a small number of children in the standard group were sleeping with a feather bedding item (table 2). Both groups had been supplied with an occlusive mattress cover, but the use of this cover was slightly higher among the standard group at trial end (table 2).

The intention-to-treat analysis found no difference in respiratory symptoms (table 3 ) or quality of life measures (table 4). $\mathrm{FEV}_{1} / \mathrm{FVC}$ was $83 \%$ for both groups, with a treatment effect size of only $0.4 \%$ ( $95 \%$ CI $-0.29 \%$ to $2.5 \%$ ). There was also no significant change in airway responsiveness measured by cold air or methacholine challenge (data not shown). These analyses were re-conducted and classified by full compliance rather than intent. The findings showed that feather pillow and quilt use tended to be associated with a decreased risk of sleep disturbed because of wheezing, with an OR of 0.34 (95\% CI 0.09 to 1.27 ) and, for severe wheeze, of 0.50 (95\% CI 0.20 to 1.24 ), although the CIs were wide because of small numbers. Child respiratory symptoms did not predict non-compliance (frequent wheeze, $p=0.25$; severe wheeze, $p=0.13$; sleep disturbed because of wheeze, $p=0.30$ ).

\section{Examination of effect modification by sleep position}

Previously the authors reported that the association between synthetic quilt use and severe wheeze was more evident in children who sleep supine. ${ }^{13}$ A similar pattern was observed here (table 5). That is, using either the intent-to-treat or the by compliance analysis, the feather group was associated with a reduced risk of sleep disturbed because of wheezing or severe wheeze to a greater extent for children who slept supine compared with those who did not. Feather bedding use was associated with a reduced risk of speech-limiting wheeze among children who slept on their back (OR $0.00,95 \%$ CI 0.00 to 0.63 , $\mathrm{p}=0.02$ ) but not among children who slept non-supine (OR 0.90, $95 \%$ CI 0.32 to $2.51, p=0.7$ ); difference in effect by sleep position, $p=0.06$. The association between feather bedding use and lung function did not differ by sleep position (data not shown).

\section{Additional analyses}

The distribution of asthma medication type and frequency of use was similar across the trial arms and further adjustment for medication use or occlusive pillow or mattress cover use at trial end did not alter the findings displayed in tables 3-5.

\section{Results for environmental aeroallergen measurement}

For inhaled exposure using NAS, data were available for 85 of 102 children, of these, 65 were above the HDM detection cutoff. Children without feather bedding $(n=43)$ were exposed to a median of $15 \mathrm{pg}$ (IOR 1.0-33.7 pg) and those with feather bedding $(n=42)$ were exposed to a median of $9.5 \mathrm{pg}$ (IOR $2.8-31.3 \mathrm{pg}$, p value for difference=0.7). For nocturnal aeroallergen collected using air filters, data were available for 100 of the 102 children, of whom 69 were above the cut-off. Children without feather bedding $(n=51)$ were exposed to a median of $28.0 \mathrm{pg} / \mathrm{m}^{3}$ of Der p 1 (IOR 1.0-66.8 pg/m³) and children with feather bedding ( $\mathrm{n}=49$ ) were exposed to a median of $16.0 \mathrm{pg} / \mathrm{m}^{3}$ Der p 1 (IOR 1.0-54.1 pg/m , p value for difference=0.3).

Table 2 Bedding characteristics of trial sample at trial end

\begin{tabular}{lcc}
\hline & Feather bedding & Standard care \\
\cline { 2 - 3 } & $\%(\mathbf{n} / \mathbf{N})$ & $\%(\mathbf{n} / \mathbf{N})$ \\
\hline Feather pillow any* & $71.3(67 / 94)$ & $3.2(3 / 94)$ \\
Feather pillow only* & $71.3(67 / 94)$ & $3.2(3 / 94)$ \\
Feather quilt any & $71.3(67 / 94)$ & $8.5(8 / 94)$ \\
Feather quilt only & $71.3(67 / 94)$ & $8.5(8 / 94)$ \\
Feather pillow and feather quilt both present & $66.0(62 / 94)$ & $0(0 / 94)$ \\
Synthetic quilt any & $5.3(5 / 94)$ & $68.1(64 / 94)$ \\
Wool quilt any & $3.2(3 / 94)$ & $16.0(15 / 94)$ \\
Wool blanket any & $6.4(6 / 94)$ & $11.7(11 / 94)$ \\
Cotton blanket any & $14.9(14 / 94)$ & $20.2(19 / 94)$ \\
Occlusive cover-pillow & $8.5(8 / 94)$ & $19.2(18 / 94)$ \\
Occlusive cover-mattress & $70.5(67 / 95)$ & $79.8(75 / 94)$ \\
Innerspring mattress & $85.1(80 / 94)$ & $84.0(79 / 94)$ \\
Mattress age $>5$ years & $85.1(80 / 94)$ & $78.7(74 / 94)$ \\
Bunk bed & $24.2(23 / 95)$ & $20.2(19 / 94)$ \\
\hline
\end{tabular}

${ }^{*}$ All other children used synthetic pillows.

Table 3 The effect of feather bedding on respiratory symptoms

\begin{tabular}{|c|c|c|c|c|}
\hline \multirow{2}{*}{$\begin{array}{l}\text { Outcome } \\
\text { (in last } 12 \text { months) }\end{array}$} & \multirow{2}{*}{$\begin{array}{l}\text { Feather bedding }(\mathrm{N}=95) \\
\%(\mathrm{n} / \mathrm{N})\end{array}$} & Standard care $(N=94)$ & \multirow[b]{2}{*}{$O R^{*}(95 \% \mathrm{Cl})$} & \multirow[b]{2}{*}{ p Value } \\
\hline & & $\mathrm{n}(\%)$ & & \\
\hline Frequent wheeze (four or more episodes) & $63.8(60 / 94)$ & $55.3(52 / 94)$ & 1.51 (0.83 to 2.76$)$ & 0.173 \\
\hline $\begin{array}{l}\text { Sleep disturbed because of wheezing } \\
\text { (1 or more nights per week) }\end{array}$ & $55.3(52 / 94)$ & $50.0(47 / 94)$ & 1.17 (0.64 to 2.13$)$ & 0.607 \\
\hline
\end{tabular}

${ }^{*}$ Adjusted for baseline measure and trial site. 


\section{DISCUSSION}

At trial end, no overall differences in respiratory symptoms, lung function or quality of life were observed 1 year after children with moderate-severe asthma and HDM sensitisation were all given a mite-occlusive mattress cover and then received either feather upper bedding (pillow and quilt) or standard bedding care. This null finding could reflect a true lack of effect or other contributing factors may have produced a false negative result.

Statistical power was adequate to detect at least a $20 \%$ reduction in the risk of frequent wheeze and trial participant retention was high. Interventions for children with asthma that are possibly mediated through allergen reduction will appear ineffective if the type of asthma is not carefully characterised and children not sensitised to the putative allergen are included. However, here, $100 \%$ of trial participants were sensitive to one or both of the two HDM species tested at baseline and all had troublesome persistent asthma based on the level of symptoms required for entry into the study. Other components of the bedding environment may also have been influential. However, a high proportion of children in both groups slept on an occlusive mattress cover (table 2) and further adjustment for pillow and mattress cover types did not alter the findings. Asthma medication type and use did not differ between groups, and adjustment for this did not alter the results; therefore medication is unlikely to have contributed to these results. Differences in laundry practices may have contributed. Non-compliance with the use of feather bedding may have contributed to the null finding.

A quarter (27 of 94) of feather group children reported using synthetic pillows at trial end and one-third were not sleeping with the feather pillow and quilt (table 2). Analysis by compliance rather than intention to treat raised the possibility that feather bedding use was associated with reduced respiratory symptoms and better lung function, a result in line with the observational epidemiological findings. ${ }^{1-6} 15232627$ However, this analysis by compliance is not conclusive because it suffers from the same potential selection bias problem as the observational studies in those children with more severe asthma who may have been less likely to maintain feather bedding use.

This study found that child sleep position influenced bedding-wheeze associations, with a protective effect of feather bedding being observed in children who slept in the supine but not the prone position. Although based on small numbers, this issue was examined a priori and the findings are consistent with previous observations that among children who slept supine, feather quilt use was associated with less frequent wheeze compared with synthetic quilt use. ${ }^{14}$ Thus, it is also possible that an interactive effect between sleep position and the bedding-wheeze association may have contributed to the null result when all sleeping positions are combined together.

Environmental Der p 1 aeroallergen levels did not differ significantly between the groups. However, both groups received mattress encasings which constituted at least some intervention and, consistent with the intention of the trial, no other measures such as regular laundry were additionally used.

In the high mite environment of Sydney, surface allergen may have accumulated similarly from non-bedding sources onto both types of bedding. In this environment, additional interventions such as frequent washing of bedding or the use of air filters could be evaluated.

Finally it should be noted that the findings from this study pertain to children with asthma and HDM sensitisation, not the child population generally. Thus a null result from this therapeutic intervention does not rule out a potential protective effect of feather bedding in relation to the inception of asthma.

In conclusion, no differences in respiratory symptoms or lung function were observed 1 year after children with moderate-severe asthma and HDM sensitisation were all given a mite-occlusive mattress cover and then received either feather upper bedding (pillow and quilt) or standard bedding care.

Table 4 The effect of feather bedding on quality of life

\begin{tabular}{|c|c|c|c|c|c|c|}
\hline \multirow[b]{3}{*}{ Measure } & \multicolumn{2}{|c|}{ Feather bedding $(n=91)$} & \multicolumn{2}{|c|}{ Standard care $(n=94)$} & \multirow{3}{*}{$\begin{array}{l}\text { Feather vs standard } \\
\text { difference* effect } \\
(95 \% \mathrm{CI})\end{array}$} & \multirow[b]{3}{*}{ p Value } \\
\hline & \multirow{2}{*}{$\frac{\text { Baseline }}{\text { Mean (SD) }}$} & \multirow{2}{*}{$\begin{array}{l}\text { Change } \\
\text { (12 months) }^{\dagger} \\
\text { Mean (SD) }\end{array}$} & \multirow{2}{*}{$\begin{array}{l}\text { Baseline } \\
\text { Mean (SD) }\end{array}$} & \multirow{2}{*}{$\begin{array}{l}\text { Change } \\
\text { (12 months) }^{\dagger} \\
\text { Mean (SD) }\end{array}$} & & \\
\hline & & & & & & \\
\hline Overall & $5.13(1.28)$ & $0.63(1.13)$ & $5.04(1.33)$ & $0.64(1.46)$ & $0.04(-0.27 \text { to } 0.35)^{\ddagger}$ & 0.80 \\
\hline Activity & $4.59(1.58)$ & $0.51(1.52)$ & $4.52(1.66)$ & $0.38(1.78)$ & $0.17(-0.23 \text { to } 0.57)^{\ddagger}$ & 0.41 \\
\hline Symptoms & $5.18(1.30)$ & $0.62(1.18)$ & $5.11(1.35)$ & $0.63(1.51)$ & $0.04(-0.28 \text { to } 0.36)^{\ddagger}$ & 0.82 \\
\hline Emotional function & $5.33(1.35)$ & $0.67(1.26)$ & $5.22(1.43)$ & $0.75(1.59)$ & $-0.01(-0.33 \text { to } 0.31)^{\ddagger}$ & 0.97 \\
\hline
\end{tabular}

*Feather minus standard: a positive value indicates greater improvement in feather bedding group.

†End point minus baseline: a positive change means an improvement.

${ }^{\ddagger}$ Adjusted for baseline measure and state.

Table 5 The association of feather upper bedding (pillow and quilt) and respiratory outcomes by intention-to-treat analysis or by actual bedding use, with further consideration of child's usual sleeping position

\begin{tabular}{|c|c|c|c|c|}
\hline \multirow{2}{*}{$\begin{array}{l}\text { Outcome } \\
\text { (in past } 12 \text { months) }\end{array}$} & $\begin{array}{l}\text { By intention to treat for } \\
\text { non-supine children } \\
(n=155)\end{array}$ & $\begin{array}{l}\text { By intention to treat for } \\
\text { supine children } \\
(n=53)\end{array}$ & $\begin{array}{l}\text { By actual feather bedding } \\
\text { use for non-supine children } \\
\text { ( } n=103 \text { ) }\end{array}$ & $\begin{array}{l}\text { By actual feather bedding } \\
\text { use for supine children } \\
(n=42)\end{array}$ \\
\hline & OR $(95 \% \mathrm{CI})$ & OR $(95 \% \mathrm{CI})$ & OR $(95 \% \mathrm{CI})$ & OR $(95 \% \mathrm{CI})$ \\
\hline $\begin{array}{l}\text { Frequent wheeze } \\
\text { (four or more episodes) }\end{array}$ & 1.80 (0.79 to 4.11$)$ & $1.24(0.33$ to 4.60$)$ & 1.88 (0.76 to 4.62$)$ & 0.61 (0.11 to 3.51 ) \\
\hline Speech-limiting wheeze & $1.38(0.57$ to 3.31$)$ & $0.35(0.08$ to 1.47$)$ & $0.90(0.32$ to 2.51$)$ & $0.00(0.00$ to 0.63$)$ \\
\hline $\begin{array}{l}\text { Sleep disturbed because of } \\
\text { wheezing } \\
\text { (1 or more nights per week) }\end{array}$ & $1.27(0.43$ to 3.79$)$ & $0.00(0.00$ to 0.93$)$ & $0.57(0.13$ to 2.36$)$ & $0.00(0.00$ to 1.39$)$ \\
\hline
\end{tabular}


The findings have implications for the policy and the design of future trials of bedding interventions for child asthma. These findings do not provide support for previous recommendations that feather bedding should be avoided for children with asthma. ${ }^{15}$ Child sleep position should be considered in the design phase and a pre-RCT washout period, to detect if parents will comply with the bedding intervention, may also be required. The potential benefit of upper bedding interventions in childhood asthma necessitates that further evaluations be undertaken with an emphasis on maintaining long-term compliance, additionally considering sleep position and focusing on the micro environment immediately adjacent to the airway of the sleeping child.

Acknowledgements The authors thank the children who participated in this study and their parents and carers. The authors thank the staff of schools, general practices and respiratory clinics for their assistance with the conduct of this study. The authors particularly thank Julie Clark, Ivan Hanigan, Anna Gear, Margherita Pitman and Merilyn McArthur.

Funding This study was funded by the National Health and Medical Research Council, Australia.

\section{Competing interests None.}

Ethics approval This study was conducted with the approval of the ACT Health Human Research Ethics Committee, the Sydney South West Area Health Service Human Research Ethics Committee and The Children's Hospital at Westmead Human Research Ethics Committee. The Australian Clinical Trial Registry Number was ACTRN12609000394246.

Provenance and peer review Not commissioned; externally peer reviewed.

\section{REFERENCES}

1. Fitzharris $\mathbf{P}$, Siebers R, Crane J. Pillow talk: have we made the wrong beds for our patients to lie in? Clin Exp Allergy 1999;29:429-32.

2. Custovic A, Woodcock A. Feather or synthetic? That is the question. Clin Exp Allergy 1999;29:144-7.

3. Zacharasiewicz A, Zidek T, Haidinger G, et al. Indoor factors and their association to respiratory symptoms suggestive of asthma in Austrian children aged 6-9 years. Wien Klin Wochenschr 1999;111:882-6.

4. Yemaneberhan $\mathbf{H}$, Bekele Z, Venn A, et al. Prevalence of wheeze and asthma and relation to atopy in urban and rural Ethiopia. Lancet 1997;350:85-90.

5. Ponsonby AL, Kemp A, Dwyer T, et al. Feather bedding and house dust mite sensitization and airway disease in childhood. J Clin Epidemiol 2002;55:556-62.

6. Nafstad P, Nystad W, Jaakkola JJ. The use of a feather quilt, childhood asthma and allergic rhinitis: a prospective cohort study. Clin Exp Allergy 2002;32:1150-4.
7. Crane J, Kemp T, Siebers R, et al. Increased house dust mite allergen in synthetic pillows may explain increased wheezing. BMJ 1997;314:1763-4.

8. Hallam C, Custovic A, Simpson B, et al. House dust mite allergen in feather and synthetic pillows. Allergy 1999;54:407-8.

9. Heyes J, Siebers R, Parkes A, et al. Beta-(1,3)-glucan levels and its determinants in New Zealand bedrooms. J Asthma 2009;46:64-6.

10. Weernink A, Severin WP, Tjernberg I, et al. Pillows, an unexpected source of Acinetobacter. J Hosp Infect 1995;29:189-99.

11. Behrens T, Maziak W, Weiland SK, et al. The use of synthetic bedding in children. Do strategies of change influence associations with asthma? J Asthma 2005;42:203-6.

12. Campbell F, Jones K. Feather vs. non-feather bedding for asthma. Cochrane Database Syst Rev 2000;4:CD002154.

13. Gotzsche PC, Hammarquist C, Burr M. House dust mite control measures in the management of asthma: meta-analysis. BMJ 1998;317:1105-10; discussion 1110.

14. Ponsonby AL, Dwyer T, Trevillian L, et al. The bedding environment, sleep position, and frequent wheeze in childhood. Pediatrics 2004;113:1216-22.

15. National Asthma Campaign. Asthma Management Handbook 1998. Melbourne: National Asthma Campaign 1998.

16. Sun JL, Wang RQ, Yin J, et al. Comparison and evaluation of several Dermatophagoides pteronyssinus allergen extracts for skin prick test. Chin Med Sci J 2009; 24:86-90.

17. Pocock S. Clinical Trials: A Practical Approach. New York: John Wiley and Sons 1998.

18. Asher MI, Weiland SK. The International Study of Asthma and Allergies in Childhood (ISAAC). ISAAC Steering Committee. Clin Exp Allergy 1998;28 (Suppl 5): 52-66; discussion 90-1.

19. Juniper EF, Guyatt GH, Feeny DH, et al. Measuring quality of life in children with asthma. Qual Life Res 1996:5:35-46.

20. Vasar M, Bråbäck L, Julge K, et al. Prevalence of bronchial hyperreactivity as determined by several methods among Estonian schoolchildren. Pediatr Allergy Immunol 1996;7:141-6.

21. Renström A, Mattsson ML, Blidberg K, et al. Nasal air sampling for measuring inhaled wheat allergen in bakeries with and without facemask use. J Occup Environ Med 2006;48:948-54

22. Tovey ER, Mitakakis TZ, Sercombe JK, et al. Four methods of sampling for dust mite allergen: differences in 'dust'. Allergy 2003;58:790-4.

23. Ponsonby AL, Dwyer T, Kemp A, et al. Synthetic bedding and wheeze in childhood. Epidemiology 2003;14:37-44.

24. Fleiss J. Statistical Methods for Rates and Proportions. 2nd edn. New York: John Wiley and Sons 1981.

25. Hosmer D, Lemeshow S. Applied Logistic Regression. 2nd edn. New York: John Wiley and Sons 2000

26. Nam HS, Park CS, Crane J, et al. Endotoxin and house dust mite allergen levels on synthetic and buckwheat pillows. J Korean Med Sci 2004;19:505-8.

27. Ohtani Y, Saiki S, Kitaichi M, et al. Chronic bird fancier's lung: histopathological and clinical correlation. An application of the 2002 ATS/ERS consensus classification of the idiopathic interstitial pneumonias. Thorax 2005;60:665-71. 